At-Tarbawi: Jurnal Pendidikan, Sosial dan Kebudayaan

Volume 8 Nomor 1 Tahun 2021

e-ISSN: 2086-9754/p-ISSN: 2086-9754

10.32505/tarbawi.v13i1.2716

\title{
Pengaruh Model Inquiry terhadap Kemampuan Memahami Teks Deskripsi pada Siswa SMP
}

\author{
Maulida Sari \\ Universitas Sains Cut Nyak Dhien \\ uscndmaulida@gmail.com
}

\begin{abstract}
The learning model is one of the important aspects of teaching. The learning model can be determined and chosen by the teacher correctly so that it is appropriate and able to teach students. The purpose of this study was to explain the effect of the inquiry learning method on the learning abilities of class VII students in the material description text. The research sample was 34 students of class VII SMP Negeri 3 Langsa City. The research method used is quasi-experimental. Research data were collected through test techniques. The research design used was a pretest-posttest control group design. Based on the application of the method, it was found that the use of the Inquiry Learning method could improve student learning outcomes. This is evidenced by the results of the $t$ test with the value of Sig. (2-tailed) of $0.000<(0.05)$. Inquiry learning classes have increased by $26 \%$. Judging from the percentage, the inquiry class is better at improving the learning outcomes of class VII students of SMPN 3 Langsa City, especially in the description text material.
\end{abstract}

Keywords: Description Text, Learning Model, Inquiry Learning.

\begin{abstract}
Abstrak
Model pembelajaran merupakan salah satu aspek penting dalam pengajaran. Model pembelajaran dapat ditentukan dan dipilih oleh guru secara benar sehingga tepat dan mampu membelajarkan siswa. Tujuan penelitian ini adalah untuk menjelaskan pengaruh metode pembelajaran ingury terhadap kemampuan belajar siswa kelas VII pada materi Teks Deskripsi. Sampel penelitian adalah 34 siswa kelas VII SMP Negri 3 Kota Langsa. Metode penelitian yang digunakan adalah kuasi eksperimen. Data penelitian dikumpulkan melalui teknik tes. Desain penelitian yang digunakan adalah pretest-posttest control group design. Berdasarkan pe nerapan metode tersebut, ditemukan bahwa penggunaan metode Inquiry Learning dapat meningkatkan hasil belajar siswa. Hal ini dibuktikan dengan hasil uji-t dengan nilai Sig. (2-tailed) sebesar 0,000< $\alpha(0,05)$. Kelas pembelajaran inkuiri mengalami peningkatan sebesar 26\%. Dilihat dari persentasenya, kelas inkuiri lebih baik dalam meningkatkan hasil belajar siswa kelas VII SMPN 3 Kota Langsa khususnya pada materi Teks Deskripsi.
\end{abstract}

Kata Kunci: Model Pembelajaran, Inquiry Learning, Teks Deskripsi. 


\section{A. Pendahuluan}

Keberhasilan pembelajaran bergantung pada beberapa hal, salah satunya adalah penggunaan model pengajaran yang digunakan oleh pendidik. Model pengajaran dapat dipilih sesuai dengan ciri khas materi dan psikologis siswa. Hal ini dimaksud agar tujuan pendidikan itu dapat tercapai. Ketercapaian tujuan tersebut tidak terlepas dari campur tangan guru di dalamnya. Jadi guru merupakan ujung tombak keberhasilan tujuan pendidikan.

SMP Negri 3 Kota Langsa merupakan salah satu sekolah menengah pertama rujukan di Kota Langsa. Sudah tentu banyak prestasi yang telah diraih oleh siswa di sekolah ini. Guru tidak menemukan kesulitan yang berarti ketika membelajarkan siswa. Sehingga banyak sudah model pembelajaran yang diterapkan di sekolah ini. Pada kesempatan ini, peneliti tertarik untuk melakukan inovasi dalam pengajaran. Salah satunya adalah dengan menerapkan model inqury.

Model pembelajaran Inquiry awalnya diperkenalkan oleh Jhon Deway pada tahun 1933-1938. Deway percaya bahwa pengetahuan guru dapat diserap siswa. Inquiry merupakan proses belajar dengan memberi peluang pada anak untuk mencari, memecahkan, hingga menemukan sendiri jawaban dari permasalahannya (Riyanto, 2011). Inquiry sangat bergantung pada ide dan pemahaman, penangkapan dan penyampaian pengalaman anak-anak yang didapat melalui dokumentasi dan tukar menukar ide dalam suatu diskusi (Abramson, 2008).

Penggunaan Inquiry sering terfokus pada aplikasi dalam pendidikan sains dan matematika, tetapi pendekatan tersebut juga cocok diterapkan pada ngajaran humaniora (Sweetland, 2008). Inquiry merupakan rangkaian kagiatan pembelajaran yang menekankan pada proses berfikir secara kritis dan analitis untuk mencari dan menemukan sendiri jawaban dari permasalahan yang dipertanyakan (Sanjaya, 2009). Inquiry juga merupakan proses belajar yang 
memberi peluang pada anak untuk mencari, memecahkan, hingga menemukan sendiri jawaban dari permasalahannya (Riyanto, 2011). Dari pernyataan di atas dapat disimpulkan bahwa Inquiry merupakan model pembelajaran yang mendorong siswa untuk mencari sendiri jawaban dari permasalahan yang sedang mereka hadapi.

Tahapan pembelajaran Inquiry pada materi teks deskripsi, Pertama, Menjelaskan tujuan dan Proses Pembelajaran. Pada tahap ini siswa diberikan arahan tentang tujuan dan proses pembelajaran. Siswa diberitahu bahwa materi pembelajaran pada pertemuan itu adalah teks deskripsi. Kedua, Menampilkan/mengamati bahan. Siswa mengamati bahan yang telah disiapkan oleh peneliti. disini peneliti telah menyiapkan sebuah gambar pemandangan hutan bakau yang terdapat di Kota Langsa. Ketiga, Menganalisis bahan. Dalam tahap ini, siswa mulai memberikan gagasan tentang apa yang diamatinya. Siswa mulai merincikan apa saja yang ada pada gambar tersebut. Keempat, Menyimpulkan pembelajaran. Pada tahap terakhir, siswa dapat menyimpulkan sendiri tentang apa yang telah ia temukan. Kemudian hasil temuannya tersebut dipresentasikan dan kelompok lain memberi tanggapan (Iskandar, 2014).

Dalam pembelajaran inquiry terdapat kelebihan dan juga kekurangan. Kelebihan metode inquiry yatu (1) metode ini merupakan strategi pembelajaran yang menekankan pada pengembangan aspek kognitif, efektif, dan psikomotor secara seimbang sehingga pembelajaran dianggap lebih bermakna. (2) dapat memberikan ruang kepada siswa untuk belajar sesuai dengan gaya belajar mereka. (3) strategi yang dianggap sesuai dengan perkembangan psikologi belajar modern yang menganggap belajar adalah proses perubahan tingkah laku berkat adanya pengalaman. (4) dapat melayani kebutuhan siswa yang memiliki kemampuan di atas rata-rata (Dapertemen Pendidikan, 2008). Sedangkan kelemahan dari penggunaan metode inquiri ini yaitu (1) jika strategi ini digunakan sebagai strategi pembelajaran, guru akan sulit mengontrol kegiatan 
dan keberhasilan siswa. (2) strategi ini sulit dalam merencanakan pembelajaran oleh karena terbentur dengan kebiasaan siswa dalam belajar. (3) kadang-kadang dalam mengimplementasikannya memerlukan waktu yang panjang sehingga guru sering mengalami kesulitan menyesuaikan dengan waktu yang telah ditentukan. (4) selama kriteria keberhasilan belajar ditentukan oleh kemampuan siswa menguasai materi pelajaran makan strategi ini akan sulit diimplementasikan oleh setiap guru (Sanjaya, Perencanaan dan Desain Sistem Pembelajaran, 2009).

Sejumlah penelitian tentang metode pembelajaran Inquiry telah banyak dilakukan. Salah satunya Endah Hendrawati. dari penelitian yang dilakukan didapat bahawa nilai rata-rata siswa SD Negri 1 Sribit mengalami peningkatan setelah menggunakan metode Inquiry (Hendrawati, 2013). Selain itu, hasil penelitian Abdi juga memberikan hasil yang serupa dengan Endah. Setelah dilakukan pembelajaran dengan menggunakan metode Inquiry selama delapan minggu, nilai siswa berangsur angsur lebih baik. Selain itu, jika dibandingkan dengan metode konvensional, nilai siswa yang diajarkan dengan menggunakan metode inquiry jauh lebih tinggi dibandingkan dengan siswa yang diajarkan dengan menggunakan metode konvensional (Abdi, 2014).

\section{B. Metode}

Pendekatan penelitian adalah pendekatan kuantitatif (Sugiono, 2014). Desain penelitian pretest posttest control grup design (Sari, 2017). Adapun desainnya ditunjukkan melalui tabel 1 di bawah ini:

Tabel 1. Desain Penelitian

\begin{tabular}{|l|c|c|c|}
\hline \multicolumn{1}{|c|}{ Kelompok } & Pre-test & Perlakuan & Post-test \\
\hline Eksperimen & $0_{1}$ & $\mathrm{X}$ & $0_{2}$ \\
\hline Kontrol & $0_{3}$ & - & $0_{4}$ \\
\hline
\end{tabular}


Keterangan:

$0_{1}=$ Nilai Pre-Test Kelas Eksperimen

$0_{2}=$ Nilai Post-Test Kelas Eksperimen

$0_{3}=$ Nilai Pre-Test Kelas Kontrol

$0_{4}=$ Nilai Post-Test Kelas Kontrol

Populasi penelitian ini adalah siswa kelas VII SMP Negri 3 Langsa yang berjumlah 384 tersebar dalam 10 kelas. Setiap kelas terdiri atas 34 hingga 38 siswa. Karena populasi relatif besar, maka dilakukan penarikan sampel. Teknik penentuan sampling yang digunakan adalah purposive sampling. purposive sampling. Sampel penelitian ini adalah siswa kelas VII SMP Negri 3 Langsa yaitu kelas VII-1 sebagai kelas eksperimen dan VII-5 sebagai kelas kontrol. Instrumen penelitian yang dilakukan adalah tes yang dilakukan sebelum dan sesudah materi ajar diberikan (Yusrizal, 2015).

\section{Hasil dan Pembahasan}

\section{Hasil}

Penelitian ini bertujuan untuk mengetahui apakah metode inquiry dapat mempengaruhi hasil belajar siswa. Untuk memperoleh jawaban dari pertanyaan tersebut, penulis membandingkan hasil belajar pre-test dan post-test dari kelas eksperimen dan kelas kontrol.

Tabel 2. Nilai Kelas Eksperimen dan Kontrol

\begin{tabular}{|l|r|r|r|r|}
\hline & $\begin{array}{c}\text { Eksperimen } \\
\text { pre-test }\end{array}$ & \multicolumn{1}{c|}{$\begin{array}{c}\text { Kontrol } \\
\text { pre-test }\end{array}$} & $\begin{array}{c}\text { Eksperimen } \\
\text { post-test }\end{array}$ & $\begin{array}{c}\text { Kontrol post- } \\
\text { test }\end{array}$ \\
\hline N $\quad$ Valid & 34 & 34 & 34 & 34 \\
Missing & 0 & 0 & 0 & 0 \\
Mean & 15.26 & 13.12 & 21.71 & 17.50 \\
Std. Error of Mean & .482 & .503 & .473 & .628 \\
Median & 15.00 & 13.00 & 21.00 & 17.00 \\
Std. Deviation & 2.810 & 2.931 & 2.758 & 3.662 \\
Range & 10 & 10 & 10 & 15 \\
Minimum & 10 & 9 & 17 & 11 \\
Maximum & 20 & 19 & 27 & 26 \\
Sum & 519 & 446 & 738 & 595 \\
\hline
\end{tabular}


Dari tabel $1 \mathrm{di}$ atas terlihat nilai ada perbedaan nilai yang diperoleh oleh siswa pada kelas eksperimen dan kelas kontrol. Pada data nilai pretes terlihat bahwa nilai rata-rata kelas kontrol adalah 13.12 sementara kelas eksperiman 15.26 dan mengalami peningkatan pada postes, kelas kontrol menjadi 17.50 dan kelas eksperimen menjadi 21.71. Selisih peningkatan pada postes adalah sebesar 4.21 .

Meskipun terlihat kedua kelas sama-sama meningkat hasil belajarnya, namun pada kelas eksperimen peningkatan tersebut sangat signifikan, yakni dari 15.26 menjadi 21.71 memiliki selisih 6.45. Sementara pada kelas kontrol selisih tersebut lebih kecil yaitu hanya 4.38. Jadi dapat dikatakan bahwa ada peningkatan nilai rata-rata kelas pada hasil belajar teks deskripsi setelah diberi perlakuan dengan model Inquiry.

Hal ini juga dapat digambarkan melalui diagram batang di bawah ini yang membandingkan nilai postes kedua kelompok:

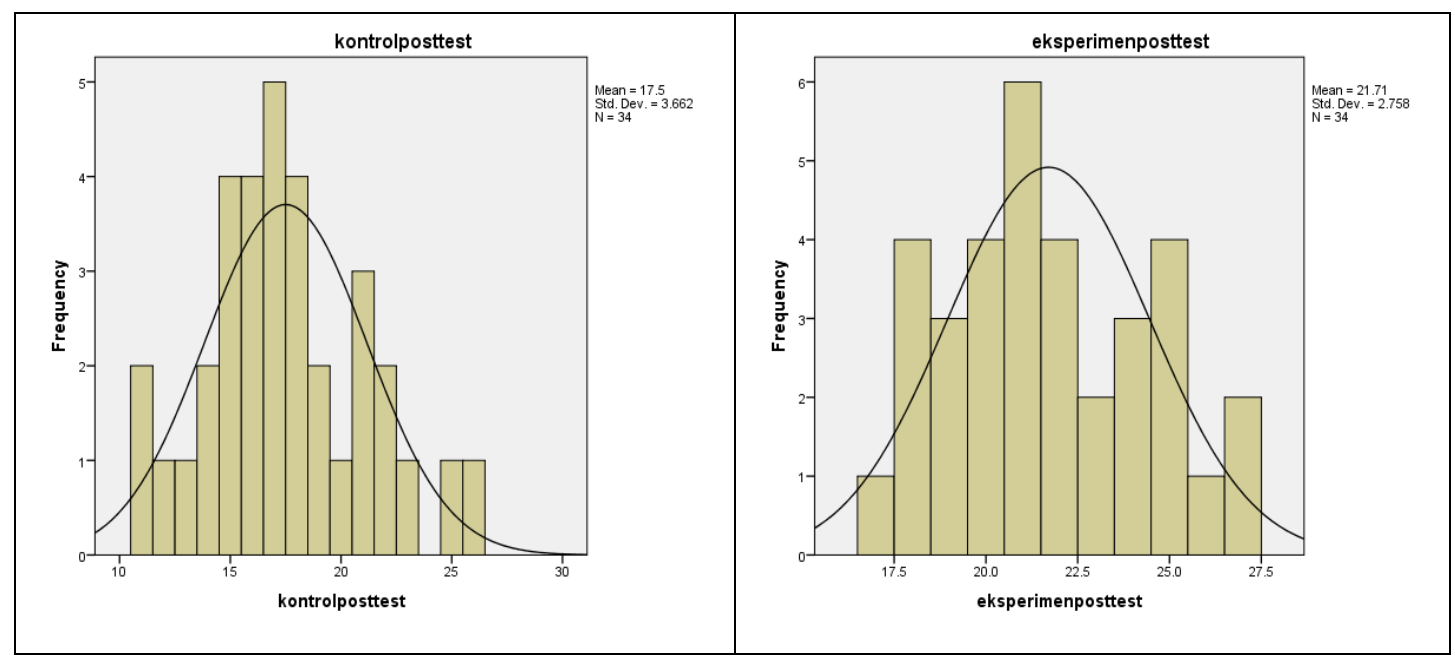

\section{Gambar 1: Diagram Distribusi Posttest Kelas Penelitian}

Dari gambar 1 di atas dapat dilihat juga perbedaan nilai rata-rata kelas yang diperoleh. Berikutnya untuk mengetahui apakah terdapat pengaruh hasil belajar siswa SMP Negri 3 Langsa setelah diterapkannya pembelajaran dengan 
menggunaan metode inquiry, peneliti menggunakan uji-t. uji-t yang digunakan yaitu uji paired simple t-test.

Tabel 3. Hasil Uji t dengan Paired Samples T-Test

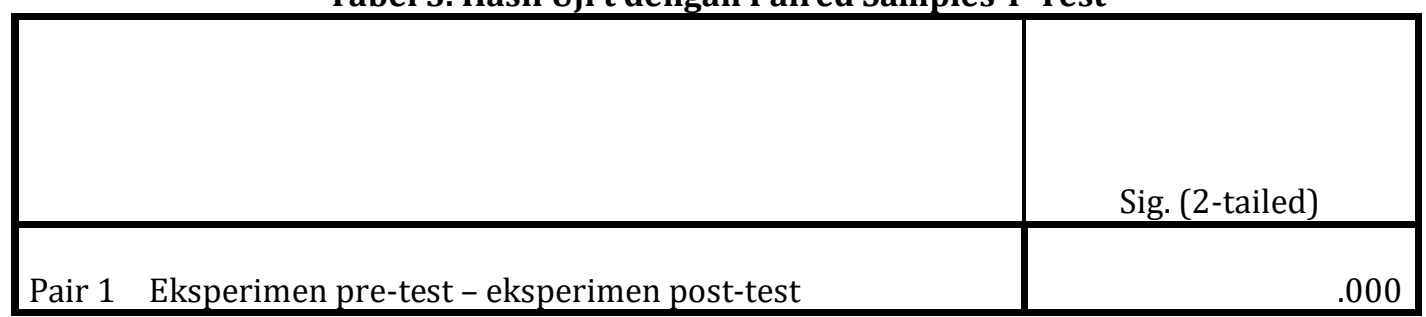

Dari hasil analisis dapat disimpulkan bahwa kelas eksperimen memiliki nilai sig. (2-tailed) 0,000 $<0,05$. Maka dari hasil perhitungan dapat dikatakan bahwa tolak $\mathrm{H}_{0}$ dan terima $\mathrm{H}_{\mathrm{a}}$ artinya terdapat perbedaan yang signifikan antara hasil belajar siswa yang diajarkan dengan model Inquiry dengan siswa yang tidak diajarkan dengan model Inquiry.

\section{Pembahasan}

Berdasarkan hasil penelitian dapat diketahui bahwa metode inquiry learning dapat mempengaruhi hasil belajar siswa SMP Negri 3 Kota Langsa. Hal ini sejalan dengan Kumairo dan Anggaryani yang mengungkap bahwa pembelajaran dengan menggunakan motode inquiry lebih baik dibandingkan dengan hassil belajar yang menggunakan metode ekspository. Pembelajaran inquiry lebih cocok diterapkan pada materi pemantulan cahaya dengan kompetensi dasar menyelidiki sifat-sifat cahaya dan hubungannya dengan berbagai bentuk cermin dan lensa (Kumairo, \& M, 2013).

Selain itu, penelitian ini juga mendukung hasil penelitian dari Hellen juga mengungkapkan bahwa pembelajaran dengan menggunakan metode inquiry memiliki hasil yang lebih baik jika dibandingkan dengan siswa yang diajarkan dengan menggunakan metode ekspository. Dan pembelajaran inquiry lebih cocok jika diterapkan pada mata pelajaran biologi atau IPA (Hellen, 2013). 


\section{Kesimpulan}

Hasil penelitian ini menunjukkan bahwa terjadi peningkatan hasil belajar siswa pada kemampuan memahami teks deskripsi pada kelas eksperiman yang diberi perlakuan dengan menggunakan model Inquiry dan kelas kontrol yang tidak diberi perlakuan dengan model Inquiry. Berdasarkan hasil penelitian maka dapat diajukan beberapa saran. Pertama, guru harus lebih membimbing siswa agar hambatan-hambatan yang sering muncul dalam proses pembelajaran dapat lebih terpantau. Kedua, penggunaan metode yag inovatif sangat diperlukan unutk memperoleh hasil belajar yang memuaskan.

\section{Daftar Pustaka}

Abdi, A. (2014). The Effect of Inquiry-Based Learning Method on Student Academic Achievement in Science Course. 2(1). Retrieved from http://hrpub.org.

Abramson, S. (2008). Co-Inquiry Documentation, Comunication and Action. Retrieved from Voice of Practitioners: http://www.naec.org

Dapertemen Pendidikan, N. (2008). Retrieved from Strategi Pembelajaran dan Pemilihan: http://www.teknologipendidikan.net

Hellen, I. (2013). Effect of Guided-Inquiry and Expository Teaching Methods on Senior Secondary School Students' Performances in Biology in Imo State, 2(4). Retrieved from http://www.apexjournal.og/JERBS

Hendrawati, E. (2013). Pengaruh Pemanfaatan Lingkungan Sebagai Sumber Belajar Melalui Metode Inquiry Terhadap Hasil Belajar Siswa SDN 1 Sribit Delanggu Pada Pelajaran IPS. Pedagogia, 2(1). Retrieved from http://journal.umsida.ac.id

Iskandar, D. (2014). Aplokasi Model dalam Pembelajaran Bahasa. Banda Aceh: Bandar Publishing.

Kumairo, , S. I., \& M, A. (2013). Studi Perbandingan Strategi Pembelajaran Ekspository dan Inquiry untuk Meningkatkan Pemahaman Siswa Kelas VIII dalam Percobaan Pemantulan Cahaya, 2(3). Retrieved from http://ejournal.unnes

Riyanto. (2011). Mendesain Pemelajaran Inovatif-Progresif. Jakarta: Kencana. 
Sanjaya, W. (2009). Perencanaan dan Desain Sistem Pembelajaran. Jakarta: Kencana.

Sanjaya, W. (2009). Strategi Pembelajaran Berorientasi Standar Proses Pendidikan. Jakarta: Kencana.

Sari, R. (2017). Pengantar Penelitian Kuantitatif. Yogyakarta: Deepublish.

Sugiono. (2014). Metode Penelitian Kuantitiatif Kualitatif dan R\&D. Bandung: Alfabeta.

Sweetland, J. (2008). Retrieved from Inquiry-Based Teching: http://www.inspiredteaching.org

Yusrizal. (2015). Tanya Jawab Seputar Pengukuran, Penilaian, dan Evaluasi Pendidikan. Banda Aceh: Syiah Kuala Universitas Press. 
